BMJ Open Sport \& Exercise Medicine

\title{
Outcomes in patients with glenoid labral lesions: a cohort study
}

\author{
Marc Zughaib, Christopher B Robbins, Bruce S Miller, Joel J Gagnier
}

To cite: Zughaib M, Robbins $\mathrm{CB}$, Miller BS, et al. Outcomes in patients with glenoid labral lesions: a cohort study. BMJ Open Sport Exerc Med 2017;2 e000209. doi:10.1136/ bmjsem-2016-000209

- Prepublication history and additional material is available. To view please visit the journal (http://dx.doi.org/ 10.1136/bmjsem-2016000209).

Accepted 31 January 2017

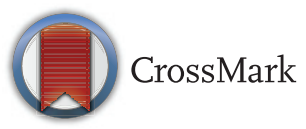

Department of Orthopaedic Surgery, University of Michigan, Ann Arbor Michigan, USA

Correspondence to Dr Joel J Gagnier; jgagnier@ med.umich.edu

\section{ABSTRACT}

Background/aim: For patients presenting with glenoid labral pathologies, there is little information on how operative interventions affect long-term outcomes and health-related quality of life (HRQoL). This study evaluated outcomes in operative and non-operative patients presenting with labral tears versus labral degenerations.

Methods: Participants completed a pain Visual Analogue Scale (VAS), the Veterans RAND 12-item Health Survey, Western Ontario Rotator Cuff Index, American Shoulder and Elbow Surgeons instrument, Scapular Assistance Test (SAT), Shoulder Activity Level, and Single Assessment Numeric Evaluation at baseline and at 6-month, 12-month and 2-year followups. $\chi^{2}$ and Student's t-test were used to test the differences between categorical and continuous variables. Analysis of variance investigated the differences between groups, and linear regression analyses explored the relationship of baseline characteristics with outcome scores.

Results: After 2 years, the operative cohort $(n=68)$ significantly improved in all measures. The nonoperative cohort $(n=55)$ showed significant improvements in all scores except the mental component summary (MCS) and pain VAS. Labral tear patients $(n=52)$ within the operative group $(n=28)$ significantly improved in all measures except MCS. Non-operative labral tear patients $(n=24)$ indicated significant improvements in all measures except MCS, VAS and SAT. Labral degeneration patients $(n=71)$ within the operative group $(n=27)$ significantly improved in all measures except MCS and SAT. Nonoperative labral degeneration patients $(n=44)$ indicated significant improvements in all measures except the physical component summary, MCS, VAS and SAT.

Conclusion: Patients who were surgically treated for labral tears or degenerations had significantly improved outcomes and HRQoL scores after 2 years compared with the non-operative cohort.

\section{INTRODUCTION}

The anatomic configuration of the shoulder joint (glenohumeral joint) is often compared with a golf ball on a tee. The labrum is a fibrocartilaginous ring that attaches to the bony rim of the glenoid fossa, ${ }^{1}$ doubling the depth of the glenoid fossa to help provide stability. ${ }^{2}$ The superior labrum attaches to the superior glenoid

\section{Key messages}

What are the new findings?

- This study highlights the impact of glenoid labral lesions in patients with rotator cuff tears on health-related quality-of-life outcomes.

- Patients with rotator cuff tear with labral pathologies tend to do worse on outcomes than those without labral pathologies.

How might it impact clinical practice in the nea future?

- This study could help guide clinicians on the importance of labral pathologies in predicting outcomes in patients with rotator cuff tear.

by loose connective fibres and provides attachment for the long head of the biceps tendon, forming the biceps anchor. The anterior superior labrum is attached to the middle and inferior glenohumeral ligaments, and the inferior labrum is attached firmly to the glenoid by inelastic fibrous tissue.

Glenoid labral lesions can often lead to significant discomfort and restriction during daily living activities, as well as various sporting activities. ${ }^{4}$ The prevalence of these tears can vary between $6 \%$ in the general population and $35 \%$ in the sporting population. ${ }^{5} 6$ The high prevalence of shoulder dysfunction is associated with high societal cost and patient burden. In 2013, a reported 86690 work-related shoulder injuries and illnesses involving days away from work occurred in the United States. ${ }^{7}$ In 2005 , the treatment measures of shoulder pain accumulated to an estimated annual cost of $\$ 39$ billion. ${ }^{8}$ Zhang et $a l^{9}$ reported the highest incidence of repair is in those aged $20-29$ years and $40-49$ years. In addition, a significant gender difference exists, with men having three times higher incidence of repair. ${ }^{9}$

Glenoid labral pathology can be classified based on location and morphology. With respect to location, the labrum can be 
divided into six areas (superior, posterosuperior, posteroinferior, inferior, anteroinferior and anterosuperior) or alternatively into clock-face 'time zones' (1-12 o'clock) (figures 1 and 2). ${ }^{10}$ Labral pathology can be classified morphologically as torn, degenerated or blunted. Diagnosis of these pathologies can be

optimally performed using magnetic resonance arthrography (MRA). Studies have shown the sensitivity of MRA to be between $82 \%$ and $100 \%$, with a specificity of between $71 \%$ and $98 \% .^{11-14}$

Tears of the superior labrum account for $80 \%-90 \%$ of labral pathology in the stable shoulder. ${ }^{15}$ These lesions were first described in 1990 by Snyder $e t a l^{16}$ as superior labrum anterior posterior (SLAP) tears. Originally SLAP tears were classified into four types (I-IV). Subsequently, lesion types V-IX were included in the classification as well. ${ }^{17} 18$ The most common mechanisms of injury include chronic, repetitive microtrauma secondary to overhead throwing-type movement or an acute fall onto the outstretched hand. ${ }^{19}$

Treatment options for patients presenting with glenoid labral pathology include both surgical and non-surgical interventions. Previous work determined that the population incidence of SLAP repairs in years 2002 and 2009 increased from 3.54 to 10.89 per $1000_{000 .}{ }^{20}$ Multiple reports document successful outcomes with operative repair of SLAP tears. ${ }^{5} 16$ 21-28 Non-operative repair of SLAP lesions has also been associated with successful outcomes. ${ }^{29}$ Edwards et al reported significant improvements in pain, function and health-related quality of life (HRQoL). The HRQoL measure is increasingly used within orthopaedic research, as clinicians increasingly look beyond strictly functional outcomes to physical, psychological and social factors. ${ }^{30}$

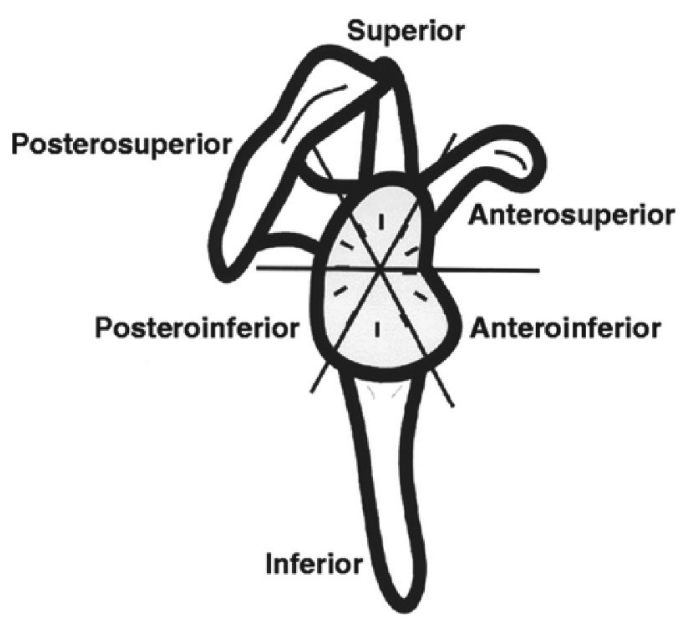

Figure 1 Labral division: six areas. Figure reproduced from Mohana-Borges et $\mathrm{al}^{10}$ with tentative permission of the American Roentgen Ray Society.

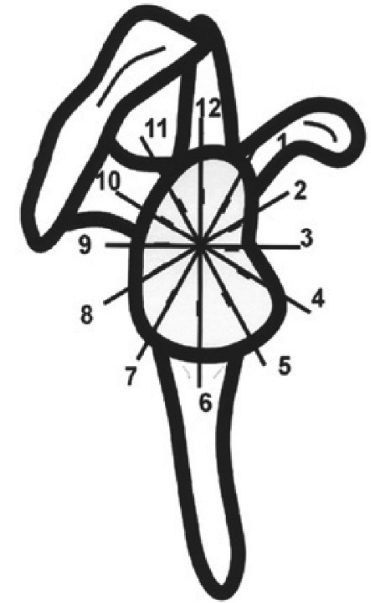

Figure 2 Labral division: time zones. For both shoulders, 12- to 6-o'clock position faces anteriorly, and 6- to 12o'clock position faces posteriorly. Figure reproduced from Mohana-Borges et $\mathrm{al}^{10}$ with tentative permission of the American Roentgen Ray Society.

Unfortunately, there is not much information on the HRQoL associated with operative interventions of labral pathology. The incentive for this shift from a biomedical model to a psychosocial model has been influenced by research addressing the relationship to HRQoL and successful outcomes within a variety of orthopaedic disciplines, including labral and rotator cuff disease. ${ }^{31-33}$ It is the intent of this research to examine the outcomes and HRQoL between operative and non-operative groups in a cohort of patients with labral pathology. The research will also compare patients presenting with labral tears with those presenting with labral degenerations.

\section{METHODS}

\section{Study design}

A cohort sample of 123 patients presenting with glenoid labral pathologies (tears or degenerations) was identified retrospectively by sampling consecutive patients from July 2012 to January 2015 from a pragmatic prospective Shoulder Registry cohort.

\section{Inclusion/exclusion criteria}

The following were the inclusion criteria: (1) greater than 18 years of age, (2) labral tear of any size and (3) the first tear of the affected shoulder. The following were the exclusion criteria: (1) a labral tear in which complete footprint coverage is not possible (for the surgical group); and (2) history of prior surgery, fracture, dislocation or infection of the affected shoulder.

\section{Data collection}

Study approval was obtained from the University of Michigan Institutional Review Board (no HUM00056320). Participants provided baseline 
demographic information and completed several previously validated paper-based outcome measures. Data collected included the pain Visual Analogue Scale (VAS), the Veterans RAND 12-Item Health Survey (VR12), Western Ontario Rotator Cuff Index (WORC), American Shoulder and Elbow Surgeons (ASES) instrument, Scapular Assistance Test (SAT), Shoulder Activity Level (SAL), and Single Assessment Numeric Evaluation (SANE). Participants were tracked for operative versus non-operative intervention and completed the same measures at baseline and at 6-month, 12-month and 2-year follow-ups (excluding SAL, which was collected at baseline only).

\section{Measures}

The primary outcome measure used was the pain VAS, which is self-completed by the respondent. The respondents are asked to place a line perpendicular to the VAS line at the point that represents their pain intensity. Using a ruler, the score is determined by measuring the distance (millimetre) on the $10 \mathrm{~cm}$ line between the 'no pain' anchor and the patient's mark, providing a range of scores from 0 to $100 .{ }^{34} \mathrm{~A}$ higher score indicates greater pain intensity.

The VR-12 Health Survey was derived from the RAND 36-item Short-Form Health Survey (SF-36). ${ }^{35-38}$ The VR-12 is a self-administered health survey used to measure HRQoL and estimate disease burden. This instrument comprises 12 items corresponding to eight principal physical and mental health domains. These domains include general health perceptions, physical functioning, role limitations due to physical and emotional problems, bodily pain, energy-fatigue, social functioning, and mental health. The 12 items are then summarised into two scores, a 'physical component summary' (PCS) score and a 'mental component summary' (MCS) score.

The WORC index is a valid, reliable and responsive HRQoL self-assessment measurement tool for shoulder disease. ${ }^{39} 40$ A recently published study determined the WORC to have the highest ratings among all shoulder instruments. ${ }^{41}$ The items included in the instrument were determined based on a literature review, along with discussions among patients, orthopaedic surgeons, sports and family physicians, and physiotherapists. The WORC includes 21 questions encompassing five domains. The domains include pain and physical symptoms (six questions), sports and recreation (four questions), work function (four questions), social function (four questions) and emotional function (three questions). In addition to these questions, a $100 \mathrm{~mm}$ VAS is included. Scores range from 0 to 100 , with a higher score indicating worse shoulder function.

The ASES shoulder outcome score was developed in 1994 in the United States by the research committee of the ASES. ${ }^{42}$ The purpose was to measure shoulder function through a physician-determined and selfassessment questionnaire. The instrument is divided into three domains: pain, instability and activities of daily living. These domains includes several yes/no questions and a VAS. A 4-point ordinal scale rates 10 questions, with a maximum score for the self-assessment portion of 30 . This score is converted to a 100 point scale (100 is the best score). The construct validity, internal consistency and reliability have been shown to be good. ${ }^{43-48}$

The SAT instrument is presumed to indirectly measure the function of the scapular rotators. ${ }^{49}$ In this test, the examiner pushes laterally and upward on the inferior medial border of the scapula to simulate the serratus anterior/lower trapezius force couple as the patient elevates the arm. According to Kibler, ${ }^{50}$ the SAT is considered positive if the manual assistance diminished or abolished the symptoms of impingement. The subject rates the pain felt while performing the movement with the assistance of the examiner on an 11-point scale. A reduction of two or more points on the 11-point numeric pain rating scale during assisted elevation, compared with elevation without assistance, is considered a positive test. Previous work has shown that a reduction of 2 points on an 11-point numeric pain rating scale represents a clinically important difference. ${ }^{51}$ This instrument has been shown to provide moderate inter-rater reliability. ${ }^{52}$

The SAL instrument generates a score based on the patient's greatest level of activity during the previous year. The most recent level of activity may be limited by other factors such as weather, conflicting commitments, or complicating illness or injury. ${ }^{53}$ The patient's greatest activity level during a 1-year period is likely to be the most accurate. ${ }^{54} \mathrm{~A}$ reasonable interpretation of the numeric activity score is high, $\geq 16($ mean $+\mathrm{SD})$; average, 7-15; and low, $\leq 6$ (mean-SD).

The SANE rating is determined by the patient's written response to the following question: 'How would you rate your shoulder today as a percentage of normal ( $0 \%$ to $100 \%$ scale, with $100 \%$ being normal)?' SANE correlates well with similar outcome scores; correlation coefficients of 0.46-0.69 have been found for SANE and ASES scores. ${ }^{55}$

\section{Statistical analysis}

A sample-size calculation was performed $(\mathrm{n}=54$, $\alpha=0.05, \beta=0.10$, effect size $=0.913$ ) using a hypothesised difference in change in pain scores in operative versus non-operative interventions $(G *$ Power v3.1.9.2). Descriptive and inferential analyses were conducted using SAS v. 9.4. $\chi^{2}$ analysis and Student's t-test were used to examine the differences between categorical and continuous variables at baseline and at 2-year follow-up. Analysis of variance was used to test the differences between groups. Data were then stratified based on labral pathology. Methods were repeated for each level of stratification.

Simple linear regression analyses were performed on statistically significant baseline characteristics within 
each strata of labral pathology. These outcome measures for patients with labral tear included pain VAS and ASES scores at baseline. For labral degeneration patients, models were created using age and ASES scores at baseline. Change in pain VAS from baseline to 2-year follow-up was used as the outcome variable for the models.

\section{RESULTS}

Participant demographics consisted of 123 patients. Of these, 82 were male and 41 were female (table 1 ). There were 68 participants in the non-operative group and 55 in the operative group. Comparing baseline demographics and clinical characteristics indicated a significant difference in age $(p=0.01)$, with non-operative patients being older. Among baseline scores, there were significant differences in pain VAS $(p=0.02)$ and baseline ASES score $(p=0.01)$, with both baseline scores indicating 'worse' scores for the operative patients. No significant differences were noted between groups for baseline PCS, MCS, WORC, SAT, SANE and SAL scores.

Paired sample t-tests within the operative group indicate significant improvements between baseline and 2year scores for pain VAS (mean difference (MD) $=-38.51, \mathrm{p}<0.01)$, PCS $(\mathrm{MD}=8.75, \mathrm{p}<0.01)$, MCS $(\mathrm{MD}=3.49, \mathrm{p}=0.05)$, ASES $(\mathrm{MD}=35.53, \mathrm{p}<0.01)$, WORC $\quad(\mathrm{MD}=-826.2, \quad \mathrm{p}<0.01), \quad$ SAT $\quad(\mathrm{MD}=9.82$, $\mathrm{p}<0.01)$ and SANE $(\mathrm{MD}=53.08, \mathrm{p}<0.01)$ (table 2). Paired sample t-tests within the non-operative group indicate significant improvements between baseline and 2-year scores for PCS $(\mathrm{MD}=3.53, \mathrm{p}=0.02)$, ASES $(\mathrm{MD}=10.63, \mathrm{p}<0.01)$, WORC $(\mathrm{MD}=-295.3, \mathrm{p}<0.01)$, SAT $(\mathrm{MD}=7.95, \mathrm{p}=0.02)$ and SANE $(\mathrm{MD}=21.89$, $\mathrm{p}<0.01)$. When comparing the difference of the 2-year means of outcome measures between groups, only MCS $(p=0.81)$ and SAT $(p=0.1)$ did not display a significant improvement.

Labral tear patient demographics consisted of 52 patients. Of these, 36 were male and 16 were female (table 3). There were 28 patients in the operative group and 24 in the non-

operative group. Comparing baseline demographics and clinical characteristics revealed no significant differences. Among baseline outcome scores, there were differences in pain VAS $(p=0.04)$ and ASES scores $(p=0.05)$. Both baseline outcome scores indicated 'worse' for the operative patients. No significant differences were noted between groups for baseline PCS, MCS, WORC, SAT, SANE and SAL scores.

Paired sample t-tests for patients with labral tear within the operative group indicate significant improvements between baseline and 2-year follow-up scores for pain VAS $(\mathrm{MD}=-43.08, \mathrm{p}<0.01)$, PCS $(\mathrm{MD}=10.81, \mathrm{p}<0.01)$, ASES $(\mathrm{MD}=35.39, \mathrm{p}<0.01)$, WORC $(\mathrm{MD}=-891.74, \mathrm{p}<0.01)$, SAT $(\mathrm{MD}=11.41$, $\mathrm{p}=0.03)$ and SANE $(\mathrm{MD}=55.08, \mathrm{p}<0.01)$ (table 4). Paired sample t-tests within the non-operative group for patients with labral tear indicate significant improvements between baseline and 2-year follow-up scores for the PCS $(\mathrm{MD}=6.89, \mathrm{p}=0.02)$, ASES $(\mathrm{MD}=7.38, \mathrm{p}<0.01)$, WORC $(\mathrm{MD}=-277.76, \mathrm{p}=0.04)$ and SANE $(\mathrm{MD}=15.55, \mathrm{p}=0.03)$. When comparing the difference of the 2-year means of outcome measures between groups, only PCS $(\mathrm{p}=0.07), \operatorname{MCS}(\mathrm{p}=0.77)$ and SAT $(p=0.07)$ did not display a significant improvement.

Labral degeneration patient demographics consisted of 71 patients. Of these, 46 were male and 25 were female (table 5). There were 27 patients in the operative group and 44 in the non-operative group. Comparing

baseline demographics and clinical characteristics indicated a significant difference in age $(p=0.01)$, with non-operative patients being older. No significant differences in outcome measures were noted between groups.

Paired sample t-tests for patients with labral degeneration within the operative group $(n=27)$ indicated significant improvements between baseline and 2-year follow-up scores for pain VAS $(\mathrm{MD}=-33.94, \mathrm{p}<0.01)$, PCS $(\mathrm{MD}=6.55, \mathrm{p}=0.01)$, ASES $(\mathrm{MD}=35.71, \mathrm{p}<0.01)$, WORC $(\mathrm{MD}=-757.06, \quad \mathrm{p}<0.01)$ and SANE $(\mathrm{MD}=51.08, \mathrm{p}<0.01)$ (table 6). Paired sample t-tests within the non-operative group $(n=44)$ for patients with labral degeneration indicate significant improvements between baseline and 2-year follow-up scores for ASES $(\mathrm{MD}=12.72, \mathrm{p}=0.01)$, WORC $(\mathrm{MD}=-305.59$, $\mathrm{p}=0.02)$ and SANE $(\mathrm{MD}=26.41, \mathrm{p}<0.01)$. When comparing the difference of the 2-year means of outcome measures between the two groups, only MCS $(p=0.51)$ and SAT $(p=0.44)$ did not display a significant improvement.

In our linear regression analyses for patients with labral tear using change in pain VAS score from baseline to 2-year follow-up as the response variable, we found baseline pain VAS $(\beta=-0.718, \mathrm{p}<0.01)$ and ASES scores $(\beta=0.597, \quad \mathrm{p}=0.03)$ were significant predictor variables. Also, in the linear regression analyses for labral degeneration, we found baseline ASES scores $(\beta=0.663, \mathrm{p}=0.02)$ to be significant predictors of change in pain.

\section{DISCUSSION}

Many published studies have demonstrated good to excellent outcomes of repairs of labral pathology. However, orthopaedic research is increasingly assessing results using HRQoL measures. In this particular patient population, the two groups were fairly homogenous regarding variables related to the injury, such as type of labral pathology, cause of injury, side of injury and symptom duration. However, the operative group was younger and had significantly worse baseline scores for pain VAS and ASES. These differences could be attributed to the guidelines and recommendations provided to 
Table 1 Demographics, clinical features and baseline outcome scores

\begin{tabular}{|c|c|c|c|c|c|c|c|}
\hline & \multicolumn{3}{|c|}{ Operative ( $n=55)$} & \multicolumn{3}{|c|}{ Non-operative (n=68) } & \multirow[b]{2}{*}{ p Value } \\
\hline & Mean/n & SD/\% & $95 \% \mathrm{Cl}$ & Mean/n & SD/\% & $95 \% \mathrm{Cl}$ & \\
\hline $\mathrm{Age}^{*}$ & 58.51 & 9.11 & 56.05 to 60.97 & 63.09 & 10.06 & 60.65 to 65.52 & 0.0100 \\
\hline Gender $\dagger$ & & & & & & & 0.3694 \\
\hline Male & 39 & 70.91 & & 43 & 63.24 & & \\
\hline Female & 16 & 29.09 & & 25 & 36.76 & & \\
\hline Body mass index* & 28.63 & 5.31 & 27.19 to 30.07 & 28.54 & 5.78 & 27.14 to 29.94 & 0.9272 \\
\hline Cause of injury $\dagger$ & & & & & & & 0.3694 \\
\hline Known & 39 & 70.91 & & 43 & 63.24 & & \\
\hline Unknown & 16 & 29.09 & & 25 & 36.76 & & \\
\hline Labral pathology $\dagger$ & & & & & & & 0.0813 \\
\hline Tear & 28 & 50.91 & & 24 & 35.29 & & \\
\hline Degeneration & 27 & 49.09 & & 44 & 64.71 & & \\
\hline Side of injury $\dagger$ & & & & & & & 0.2655 \\
\hline Right & 31 & 56.36 & & 45 & 66.18 & & \\
\hline Left & 24 & 43.64 & & 43 & 33.82 & & \\
\hline Symptom duration $\dagger$ & & & & & & & 0.4084 \\
\hline$<1$ year & 21 & 38.18 & & 31 & 45.59 & & \\
\hline$>1$ year & 34 & 61.82 & & 27 & 54.41 & & \\
\hline Diabetes $\dagger$ & & & & & & & 0.4529 \\
\hline Yes & 7 & 12.73 & & 12 & 17.65 & & \\
\hline No & 48 & 87.27 & & 56 & 82.35 & & \\
\hline Smoking $\dagger$ & & & & & & & 0.7559 \\
\hline Yes & 4 & 7.27 & & 4 & 5.88 & & \\
\hline No & 51 & 92.73 & & 64 & 94.12 & & \\
\hline Pain VAS* & 54.31 & 26.26 & 46.99 to 61.62 & 42.57 & 26.93 & 35.95 to 49.19 & 0.0191 \\
\hline Baseline PCS* & 39.11 & 9.02 & 36.14 to 42.07 & 40.03 & 8.66 & 37.49 to 42.58 & 0.6308 \\
\hline Baseline MCS $\ddagger$ & 48.50 & 11.24 & 44.81 to 52.19 & 51.47 & 10.22 & 48.47 to 54.47 & 0.2909 \\
\hline Baseline ASES* & 50.63 & 21.30 & 44.64 to 56.62 & 60.73 & 20.67 & 55.34 to 66.12 & 0.0132 \\
\hline Baseline WORC* & 1184.30 & 455.20 & 1058.80 to 1309.80 & 1061.90 & 453.90 & 947.60 to 1176.20 & 0.1512 \\
\hline SAT $\ddagger$ & 79.20 & 26.08 & 71.55 to 86.86 & 70.23 & 33.10 & 61.28 to 79.18 & 0.1726 \\
\hline SANE $\ddagger$ & 30.94 & 24.04 & 24.32 to 37.57 & 37.34 & 22.88 & 31.67 to 43.01 & 0.0819 \\
\hline
\end{tabular}

*p values calculated using t-tests.

$\dagger p$ values calculated using Wilcoxon signed-rank tests.

$\ddagger p$ values calculated using chi-square tests.

Continuous data presented as mean, SD. Categorical data presented as $\mathrm{n}(\%)$.

ASES, American Shoulder and Elbow Surgeons; MCS, mental component summary; PCS, physical component summary; SAL, Shoulder Activity Level; SANE, Single Assessment Numeric Evaluation; SAT, Scapular Assistance Test; VAS, Visual Analogue Scale; WORC, Western Ontario Rotator Cuff Index.

physicians for determining whether a patient should elect operative or non-operative treatment. The patient who elected operative intervention experienced significantly improved long-term HRQoL outcomes and function scores. This trend held true after stratification by labral pathology, as operative patients consistently reported more favourable outcome scores after the 2-year follow-up period.

In this patient population, pain VAS was significantly higher in the operative group at baseline. However, 


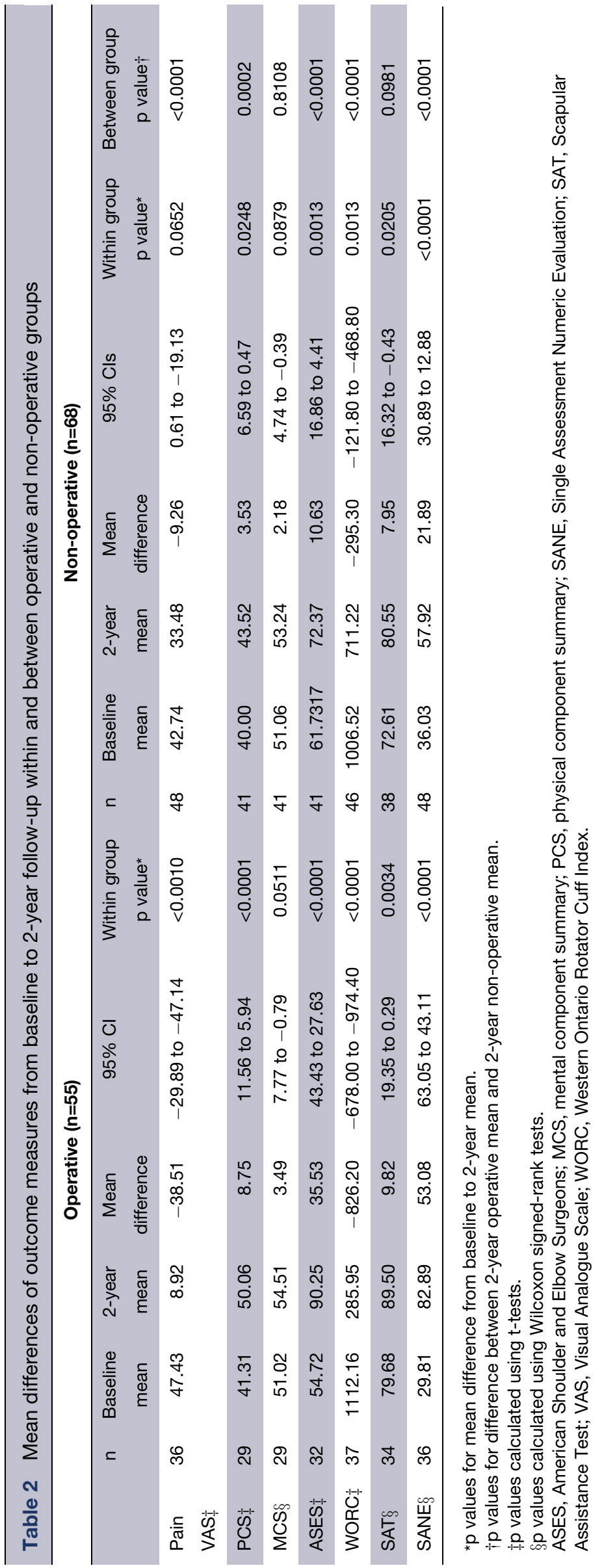


Table 3 Labral tear demographics, clinical features and baseline outcome scores

\begin{tabular}{|c|c|c|c|c|c|c|c|}
\hline & \multicolumn{3}{|c|}{ Operative $(n=28)$} & \multicolumn{3}{|c|}{ Non-operative $(n=24)$} & \multirow[b]{2}{*}{ p Value } \\
\hline & Mean (n) & SD (\%) & $95 \% \mathrm{Cl}$ & Mean (n) & SD (\%) & $95 \% \mathrm{Cl}$ & \\
\hline Age $^{*}$ & 57.89 & 9.27 & 54.30 to 61.49 & 59.33 & 11.74 & 54.38 to 64.29 & 0.6232 \\
\hline Gender $\dagger$ & & & & & & & 0.3303 \\
\hline Male & 21 & 75.00 & & 15 & 53.57 & & \\
\hline Female & 7 & 25.00 & & 9 & 46.43 & & \\
\hline Body mass index* & 27.24 & 5.46 & 25.12 to 29.36 & 27.80 & 6.32 & 25.13 to 30.47 & 0.7310 \\
\hline Cause of injury $\dagger$ & & & & & & & 0.6250 \\
\hline Known & 21 & 75.00 & & 18 & 64.29 & & \\
\hline Unknown & 7 & 25.00 & & 6 & 35.71 & & \\
\hline Side of injury $\dagger$ & & & & & & & 0.5479 \\
\hline Right & 14 & 50.00 & & 14 & 58.33 & & \\
\hline Left & 14 & 50.00 & & 10 & 41.67 & & \\
\hline Symptom duration $\dagger$ & & & & & & & 0.6856 \\
\hline$<1$ year & 9 & 32.14 & & 9 & 37.50 & & \\
\hline$>1$ year & 19 & 67.86 & & 15 & 62.50 & & \\
\hline Diabetes $\dagger$ & & & & & & & 0.1103 \\
\hline Yes & 1 & 3.57 & & 4 & 14.29 & & \\
\hline No & 27 & 96.43 & & 20 & 85.71 & & \\
\hline Smoking $\dagger$ & & & & & & & 0.8408 \\
\hline Yes & 3 & 10.71 & & 3 & 10.71 & & \\
\hline No & 25 & 89.29 & & 25 & 89.29 & & \\
\hline Pain VAS* & 57.36 & 27.71 & 45.92 to 68.80 & 40.58 & 27.29 & 29.06 to 52.11 & 0.0381 \\
\hline Baseline PCS* & 36.83 & 7.89 & 33.03 to 40.64 & 37.90 & 10.45 & 32.70 to 43.10 & 0.7271 \\
\hline Baseline MCS $\ddagger$ & 48.57 & 11.85 & 42.86 to 54.29 & 51.38 & 10.01 & 46.41 to 56.36 & 0.5136 \\
\hline Baseline ASES* & 51.27 & 22.33 & 42.25 to 60.29 & 63.90 & 20.37 & 54.63 to 73.18 & 0.0510 \\
\hline Baseline WORC* & 1209.60 & 444.80 & 1033.70 to 1385.60 & 1042.90 & 476.80 & 831.50 to 1254.30 & 0.2126 \\
\hline SAT & 79.45 & 26.12 & 67.87 to 91.04 & 62.81 & 38.03 & 45.50 to 80.12 & 0.2431 \\
\hline SANE $\ddagger$ & 27.94 & 22.10 & 19.01 to 36.87 & 39.50 & 24.71 & 29.07 to 49.93 & 0.0754 \\
\hline$S A L^{*}$ & 11.21 & 8.60 & 8.61 to 13.81 & 9.76 & 4.51 & 7.45 to 12.08 & 0.3925 \\
\hline
\end{tabular}

* $p$ values calculated using t-tests.

$\dagger p$ values calculated using $\chi^{2}$ tests.

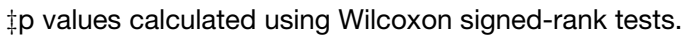

Continuous data presented as mean, SD. Categorical data presented as $\mathrm{n}(\%)$.

ASES, American Shoulder and Elbow Surgeons; MCS, mental component summary; PCS, physical component summary; SAL, Shoulder Activity Level; SANE, Single Assessment Numeric Evaluation; SAT, Scapular Assistance Test; VAS, Visual Analogue Scale; WORC, Western Ontario Rotator Cuff Index.

there was evidence to support the efficacy of surgical intervention as these patients electing operative treatment displayed significant improvements from baseline to 2-year follow-up across all outcome measures. While the non-operative group also reported significant improvements in outcome measures, the operative group exhibited larger MDs from baseline to follow-up, as well as higher scores associated with better outcomes. Additionally, the reported raw 2-year follow-up scores were significantly higher/improved when compared with the non-operative group except for MCS and SAT.

Although numerous studies explicitly examine the functional outcomes following labrum repair, ${ }^{5} 16$ 22-24 


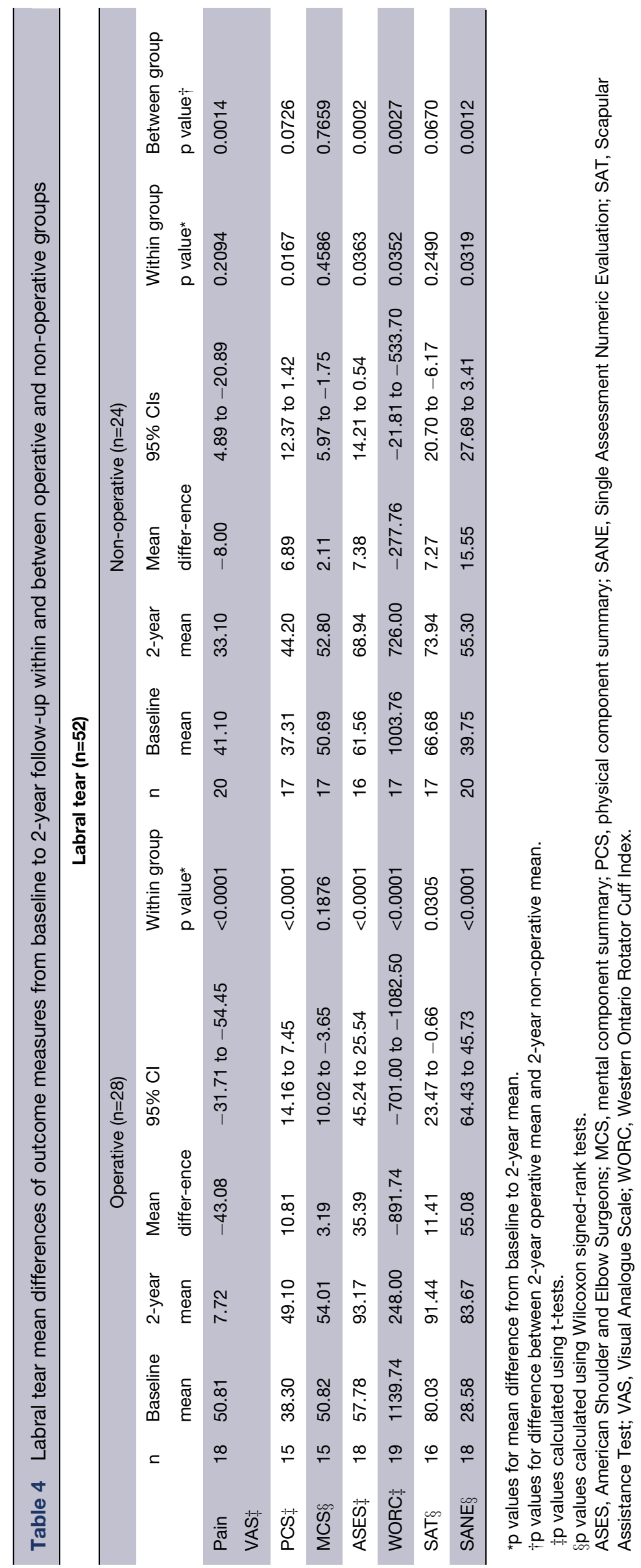


Table 5 Labral degeneration demographics, clinical features and baseline outcome scores

\begin{tabular}{|c|c|c|c|c|c|c|c|}
\hline & & Operat & $(n=27)$ & & Von-oper & ve $(n=44)$ & \\
\hline & Mean/n & $\mathrm{SD} / \%$ & $95 \% \mathrm{Cl}$ & Mean/n & $\mathrm{SD} / \%$ & $95 \% \mathrm{Cl}$ & $p$ Value \\
\hline Age $^{*}$ & 59.15 & 9.07 & 55.56 to 62.73 & 65.14 & 8.48 & 62.56 to 67.72 & 0.0064 \\
\hline Gender $\dagger$ & & & & & & & 0.7952 \\
\hline Male & 18 & 66.67 & & 28 & 63.64 & & \\
\hline Female & 9 & 33.33 & & 16 & 36.36 & & \\
\hline Body mass index* & 30.07 & 4.84 & 28.15 to 31.99 & 28.94 & 5.50 & 27.26 to 30.61 & 0.3815 \\
\hline Cause of injury $\dagger$ & & & & & & & 0.4098 \\
\hline Known & 18 & 66.67 & & 25 & 56.82 & & \\
\hline Unknown & 9 & 33.33 & & 19 & 43.18 & & \\
\hline Side of injury $\dagger$ & & & & & & & 0.5126 \\
\hline Right & 17 & 62.96 & & 31 & 70.45 & & \\
\hline Left & 10 & 37.04 & & 13 & 29.55 & & \\
\hline Symptom duration $\dagger$ & & & & & & & 0.6492 \\
\hline$<1$ year & 15 & 55.56 & & 22 & 50 & & \\
\hline$>1$ year & 12 & 44.44 & & 22 & 50 & & \\
\hline Diabetes $\dagger$ & & & & & & & 0.6779 \\
\hline Yes & 6 & 22.22 & & 8 & 18.18 & & \\
\hline No & 21 & 77.78 & & 36 & 81.82 & & \\
\hline Smoking $\dagger$ & & & & & & & 0.7235 \\
\hline Yes & 1 & 3.70 & & 1 & 2.27 & & \\
\hline No & 26 & 96.30 & & 43 & 97.73 & & \\
\hline Pain VAS* & 51.48 & 25.02 & 41.58 to 61.38 & 43.70 & 27.00 & 35.29 to 52.11 & 0.2338 \\
\hline Baseline PCS* & 41.38 & 9.70 & 36.70 to 46.05 & 41.36 & 7.23 & 38.61 to 44.11 & 0.9937 \\
\hline Baseline MCS $\ddagger$ & 48.43 & 10.91 & 43.17 to 53.69 & 51.52 & 10.53 & 47.51 to 55.53 & 0.4231 \\
\hline Baseline ASES* & 49.96 & 20.61 & 41.45 to 58.47 & 58.97 & 20.89 & 52.11 to 65.84 & 0.0973 \\
\hline Baseline WORC* & 1158.00 & 473.10 & 966.90 to 1349.10 & 1072.10 & 446.80 & 931.10 to 1213.10 & 0.4562 \\
\hline SAT $\ddagger$ & 78.98 & 26.58 & 68.01 to 89.95 & 74.81 & 29.32 & 64.58 to 85.04 & 0.4518 \\
\hline SANE $\ddagger$ & 33.83 & 25.86 & 23.60 to 44.06 & 36.07 & 21.96 & 29.14 to 43.01 & 0.5185 \\
\hline SAL* & 10.69 & 3.86 & 8.63 to 12.74 & 11.76 & 5.01 & 9.48 to 14.04 & 0.4816 \\
\hline
\end{tabular}

*p values calculated using t-tests.

$\dagger p$ values calculated using $\chi^{2}$ tests.

$\pm \mathrm{p}$ values calculated using Wilcoxon signed-rank tests.

Continuous data presented as mean, SD. Categorical data presented as $\mathrm{n}(\%)$.

ASES, American Shoulder and Elbow Surgeons; MCS, mental component summary; PCS, physical component summary; SAL, Shoulder Activity Level; SANE, Single Assessment Numeric Evaluation; SAT, Scapular Assistance Test; VAS, Visual Analogue Scale; WORC, Western Ontario Rotator Cuff Index.

${ }^{27}$ few studies look at the relationship between labral pathology and quality of life. The HRQoL outcomes for participants in the present study support previous research that has been conducted with non-operative patients. While the present study used the VR-12 as the HRQoL measure, studies that have used different
HRQoL measures have reported similar results. Edwards $e t a l^{29}$ found in non-operative patients that the SF-36, ASES and VAS scores all improved at final follow-up.

VR-12 (MCS and PCS) scores were not significantly different at baseline between operative and non- 


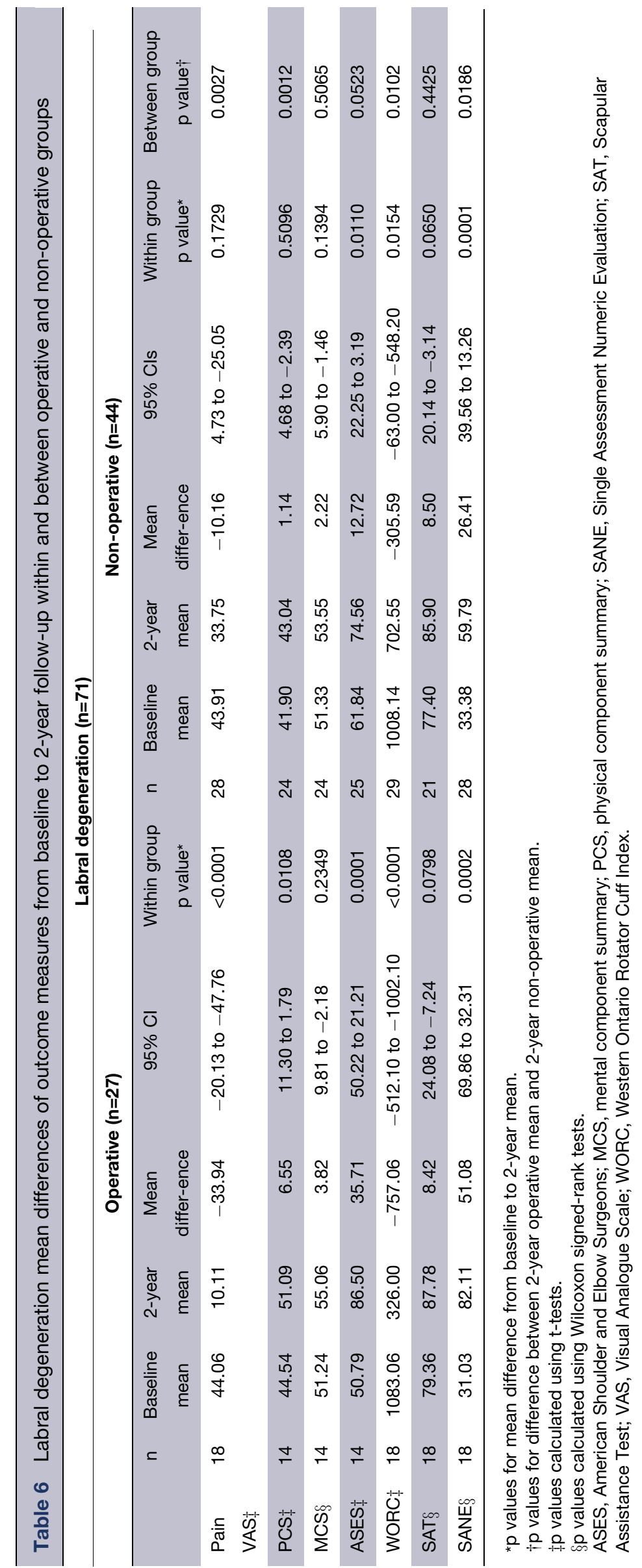


operative groups. Despite observing an increased MCS score in both operative and non-operative groups, there was no statistical difference between 2-year MCS scores of either treatment group. Throughout this study, MCS consistently did not display significant improvements over time. This phenomenon is not fully understood, but can possibly be attributed to the nature of a repaired labrum. Previous research involving overhead athletes receiving non-operative treatments of SLAP tears found return to sport difficult to achieve, despite improvement in pain $\operatorname{scores}^{29}$ : 'Although $71 \%$ of patients returned to the same or better levels of participation, only 10 of the 15 overhead athletes $(67 \%)$ returned to their overhead sport at the same or higher level'. ${ }^{29}$ Additionally, Cohen $e t a l^{21}$ found that only 14 of 29 patients (48\%) in their series could return to pre-participation levels after SLAP repair, and only $71 \%$ of patients were satisfied. This may suggest that patients in our population experienced less pain and higher PCS scores, but did not report increased MCS scores due to disappointing results when returning to sport or work.

Stratifying by labral pathology allowed a deeper look into the relationship between treatment and HRQoL. Among patients with labral tears, the two groups were fairly homogenous except for the operative group presenting significantly worse baseline scores for pain VAS and ASES. As previously mentioned, this difference is likely the result of physician guidelines and recommendations for patients presenting with higher levels of pain. In this population, only the operative group reported a significant improvement in pain VAS scores. Both groups displayed significant improvement in PCS scores from baseline to 2-year follow-up, with operative patients reporting a nearly statistically greater improvement in PCS scores. The efficacy of operative treatment of labral tears has been shown again, as operative patients displayed larger improvement in pain VAS, ASES, WORC and SANE scores when compared with non-operative patients.

Patients presenting with labral degenerations reported improvements in outcome scores. However, it is important to note non-significant improvements in pain VAS and PCS scores in patients receiving nonoperative treatment. Operative patients reported significant improvements in these scores, further supporting surgical treatment of labral pathologies. While it may seem intuitive for a physician to treat a less severe lesion with a conservative approach, this stratified non-operative group displayed the smallest MD in scores from baseline to 2-year follow-up.

Study limitations include single-centre patient information, as well as smaller sample sizes after stratification. Additionally, the patient population was derived from patients presenting with rotator cuff pathology. Despite controlling for this variable, it may prove useful to investigate the effects of treatment on patients presenting specifically with labral pathology.
Future research may include additional long-term trials evaluating HRQoL in patients choosing operative and non-operative treatment modalities.

The present study provides important information on expected outcomes in patients who receive operative or non-operative treatment for labral pathologies, and may help guide decisions on when to consider intervention types based on these criteria. Operative groups in this cohort consistently exhibited larger MDs for all outcome measures, and higher scores associated with better outcomes. This study demonstrates that patients who received operative treatment of labral pathology (either a tear or degeneration) significantly improved HRQoL and outcome scores after 2 years when compared with non-operative treatment.

Open Access This is an Open Access article distributed in accordance with the Creative Commons Attribution Non Commercial (CC BY-NC 4.0) license, which permits others to distribute, remix, adapt, build upon this work noncommercially, and license their derivative works on different terms, provided the original work is properly cited and the use is non-commercial. See: http:// creativecommons.org/licenses/by-nc/4.0/

(c) Article author(s) (or their employer(s) unless otherwise stated in the text of the article) 2017. All rights reserved. No commercial use is permitted unless otherwise expressly granted.

\section{REFERENCES}

1. Wilk KE, Reinold MM, Dugas JR, et al. Current concepts in the recognition and treatment of superior labral (SLAP) lesions. J Orthop Sports Phys Ther 2005;35:273-91.

2. Perry J. Anatomy and biomechanics of the shoulder in throwing, swimming, gymnastics, and tennis. Clin Sports Med 1983;2:247-70.

3. Robinson G, Ho Y, Finlay K, et al. Normal anatomy and common labral lesions at MR arthrography of the shoulder. Clin Radiol 2006;61:805-21.

4. Vander Kraats R, Doss A. Glenoid labral tear follow up case series on ultrasound guided autologous platelet rich plasma in conjunction with a progressive rehabilitation program. F1000Res 2012;1:68.

5. Funk L, Snow M. SLAP tears of the glenoid labrum in contact athletes. Clin J Sport Med 2007;17:1-4.

6. Handelberg F, Willems S, Shahabpour M, et al. SLAP lesions: a retrospective multicenter study. Arthroscopy 1998;14:856-62.

7. U.S Department of Labor. Bureau of Labor Statistics. Nonfatal occupational injuries and illnesses requiring days away from work. 2014. http://www.bls.gov/news.release/pdf/osh2.pdf (accessed 16 Dec 2015).

8. Johnson MP, Crossley KL, O'Neil ME, et al. Estimates of direct health care expenditures among individuals with shoulder dysfunction in the United States. APTA combined sections meeting abstract no. PL8. J Orthop Sports Phys Ther 2005;35:A4.

9. Zhang AL, Kreulen C, Ngo SS, et al. Demographic trends in arthroscopic SLAP repair in the United States. Am J Sports Med 2012;40:1144-7.

10. Mohana-Borges AV, Chung CB, Resnick D. Superior labral anteroposterior tear: classification and diagnosis on MRI and MR arthrography. AJR Am J Roentgenol 2003;181:1449-62.

11. Bencardino JT, Beltran J, Rosenberg ZS, et al. Superior labrum anterior-posterior lesions: diagnosis with MR arthrography of the shoulder. Radiology 2000;214:267-71.

12. Dinauer PA, Flemming DJ, Murphy KP, et al. Diagnosis of superior labral lesions: comparison of noncontrast MRI with indirect MR arthrography in unexercised shoulders. Skeletal Radiol 2007;36:195-202.

13. Herold T, Hente R, Zorger N, et al. Indirect MR-arthrography of the shoulder-value in the detection of SLAP-lesions. Rofo 2003;175:1508-14

14. Waldt S, Burkart A, Lange $P$, et al. Diagnostic performance of MR arthrography in the assessment of superior labral anteroposterior lesions of the shoulder. AJR Am J Roentgenol 2004;182:1271-8.

15. Clavert P. Glenoid labrum pathology. Orthop Traumatol Surg Res 2015;101(1 Suppl):S19-24. 
16. Snyder SJ, Banas MP, Karzel RP. An analysis of 140 injuries to the superior glenoid labrum. J Shoulder Elbow Surg 1995;4:243-8.

17. Maffet MW, Gartsman GM, Moseley B. Superior labrum-biceps tendon complex lesions of the shoulder. Am J Sports Med 1995;23:93-8.

18. Solomon DJ, Levine WN. SLAP tears: pearls and pitfalls in diagnosis and management. Sports Med Update 2011:2-6.

19. Rowbotham EL, Grainger AJ. Superior labrum anterior to posterior lesions and the superior labrum. Semin Musculoskelet Radiol 2015;19:269-76.

20. Vogel LA, Moen TC, Macaulay AA, et al. Superior labrum anterior-toposterior repair incidence: a longitudinal investigation of community and academic databases. J Shoulder Elbow Surg 2014;23:e119-26.

21. Cohen DB, Coleman S, Drakos MC, et al. Outcomes of isolated type II SLAP lesions treated with arthroscopic fixation using a bioabsorbable tack. Arthroscopy 2006;22:136-42.

22. Field LD, Savoie FH. Arthroscopic suture repair of superior labral detachment lesions of the shoulder. Am J Sports Med 1993;21:783-90.

23. Nam EK, Snyder SJ. The diagnosis and treatment of superior labrum, anterior and posterior (SLAP) lesions. Am J Sports Med 2003;31:798-810.

24. O'Brien SJ, Allen AA, Coleman SH, et al. The trans-rotator cuff approach to SLAP lesions: technical aspects for repair and a clinical follow-up of 31 patients at a minimum of 2 years. Arthroscopy 2002;18:372-7.

25. Pagnani MJ, Speer KP, Altchek DW, et al. Arthroscopic fixation of superior labral lesions using a biodegradable implant: a preliminary report. Arthroscopy 1995;11:194-8.

26. Resch $\mathrm{H}$, Golser $\mathrm{K}$, Thoeni $\mathrm{H}$, et al. Arthroscopic repair of superior glenoid labral detachment (the SLAP lesion). J Shoulder Elbow Surg 1993;2:147-55.

27. Rhee YG, Lee DH, Lim CT. Unstable isolated SLAP lesion: clinical presentation and outcome of arthroscopic fixation. Arthroscopy 2005;21:1099.e1-1099.e7.

28. Yoneda M, Hirooka A, Saito S, et al. Arthroscopic stapling for detached superior glenoid labrum. J Bone Joint Surg Br 1991;73:746-50.

29. Edwards SL, Lee JA, Bell JE, et al. Nonoperative treatment of superior labrum anterior posterior tears: improvements in pain, function, and quality of life. Am J Sports Med 2010;38:1456-61.

30. Cho $\mathrm{CH}$, Song KS, Hwang I, et al. Does rotator cuff repair improve psychologic status and quality of life in patients with rotator cuff tear? Clin Orthop Relat Res 2015;473:3494-500.

31. Ayers DC, Franklin PD, Ring DC. The role of emotional health in functional outcomes after orthopaedic surgery: extending the biopsychosocial model to orthopaedics: AOA critical issues. J Bone Joint Surg Am 2013;95:e165-1-7.

32. Chung SW, Park JS, Kim SH, et al. Quality of life after arthroscopic rotator cuff repair: evaluation using SF-36 and an analysis of affecting clinical factors. Am J Sports Med 2012;40:631-9.

33. Mohtadi NG, Hollinshead RM, Sasyniuk TM, et al. A randomized clinical trial comparing open to arthroscopic acromioplasty with miniopen rotator cuff repair for full-thickness rotator cuff tears: diseasespecific quality of life outcome at an average 2-year follow-up. Am J Sports Med 2008;36:1043-51.

34. Jensen MP, Karoly P, Braver S. The measurement of clinical pain intensity: a comparison of six methods. Pain 1986;27:117-26.

35. Hays RD, Sherbourne CD, Mazel RM. The RAND 36-Item Health Survey 1.0. Health Econ 1993;2:217-27.
36. Kazis LE, Miller DR, Skinner KM, et al. Applications of methodologies of the Veterans Health Study in the VA Healthcare system: conclusions and summary. J Ambul Care Manage 2006;29:182-8

37. Kazis LE, Miller DR, Skinner KM, et al. Patient-reported measures of health: The Veterans Health Study. J Ambul Care Manage 2004;27:70-83.

38. Kazis LE, Selim A, Rogers W, et al. Dissemination of methods and results from the veterans health study: final comments and implications for future monitoring strategies within and outside the veterans healthcare system. J Ambul Care Manage 2006;29:310-9.

39. Kirkley A, Griffin S, Dainty K. Scoring systems for the functional assessment of the shoulder. Arthroscopy 2003;19:1109-20.

40. Lopes AD, Ciconelli RM, Carrera EF, et al. Validity and reliability of the Western Ontario Rotator Cuff Index (WORC) for use in Brazil. Clin J Sport Med 2008:18:266-72.

41. Huang H, Grant JA, Miller BS, et al. A systematic review of the psychometric properties of patient-reported outcome instruments for use in patients with rotator cuff disease. Am J Sports Med 2015;43:2572-82.

42. Richards RR, An KN, Bigliani LU, et al. A standardized method for the assessment of shoulder function. J Shoulder Elbow Surg 1994;3:347-52.

43. Angst F, Goldhahn J, Drerup S, et al. Responsiveness of six outcome assessment instruments in total shoulder arthroplasty. Arthritis Rheum 2008;59:391-8.

44. Beaton D, Richards RR. Assessing the reliability and responsiveness of 5 shoulder questionnaires. J Shoulder Elbow Surg 1998;7:565-72.

45. Beaton DE, Richards RR. Measuring function of the shoulder. A cross-sectional comparison of five questionnaires. J Bone Joint Surg Am 1996;78:882-90.

46. Bot SD, Terwee CB, van der Windt DA, et al. Clinimetric evaluation of shoulder disability questionnaires: a systematic review of the literature. Ann Rheum Dis 2004;63:335-41.

47. Kocher MS, Horan MP, Briggs KK, et al. Reliability, validity, and responsiveness of the American Shoulder and Elbow Surgeons subjective shoulder scale in patients with shoulder instability, rotator cuff disease, and glenohumeral arthritis. J Bone Joint Surg Am 2005;87:2006-11.

48. Michener LA, McClure PW, Sennett BJ. American Shoulder and Elbow Surgeons standardized shoulder assessment form, patient self-report section: reliability, validity, and responsiveness. $J$ Shoulder Elbow Surg 2002;11:587-94.

49. Borstad JD, Ludewig PM. The effect of long versus short pectoralis minor resting length on scapular kinematics in healthy individuals. $J$ Orthop Sports Phys Ther 2005;35:227-38.

50. Kibler WB. The role of the scapula in athletic shoulder function. $A m \mathrm{~J}$ Sports Med 1998;26:325-37.

51. Farrar JT, Young JP, LaMoreaux L, et al. Clinical importance of changes in chronic pain intensity measured on an 11-point numerical pain rating scale. Pain 2001;94:149-58.

52. Rabin A, Irrgang JJ, Fitzgerald GK, et al. The intertester reliability of the Scapular Assistance Test. J Orthop Sports Phys Ther 2006;36:653-60.

53. Brophy RH, Beauvais RL, Jones EC, et al. Measurement of shoulder activity level. Clin Orthop Relat Res 2005;439:101-8.

54. Marx RG, Stump TJ, Jones EC, et al. Development and evaluation of an activity rating scale for disorders of the knee. Am J Sports Med 2001;29:213-8

55. Williams GN, Gangel TJ, Arciero RA, et al. Comparison of the single assessment numeric evaluation method and two shoulder rating scales. outcomes measures after shoulder surgery. $\mathrm{Am} J$ Sports Med 1999:27:214-21. 